\title{
International stays abroad, collaborations and the return of Spanish researchers
}

\author{
Inés Andújar ${ }^{1}$, Carolina Cañibano ${ }^{2}$ and Ana Fernandez-Zubieta ${ }^{1}$
}

\author{
1. IESA-CSIC (Instituto de Estudios Sociales Avanzados), Spain \\ 2. INGENIO (CSIC-UPV), Universitat Politècnica de Valencia, Spain
}

\begin{abstract}
This paper uses curricular information from a sample of applicants to the Spanish Ramón y Cajal program to, on the one hand, assess the extent to which international mobility has an impact on the collaboration patterns of researchers and, on the other hand, to address the connection between collaboration patterns and the likelihood of return to Spain. We focus on two main types of collaborations: copublications and collaboration in research projects through formal participation. We find that longer stays abroad seem to provide better opportunities to publish with a host principal investigator and to participate in research projects in the recipient country. We find that the length of the stay also has an impact on the likelihood of return to Spain: longer stays abroad reduce the likelihood of return. However, a longer duration international stay does not affect the collaboration links maintained with the home country, which may persist over time. We also find that public financial support is crucial for explaining and facilitating the return of Spanish researchers from abroad.
\end{abstract}




\section{Introduction}

Scientific mobility and migration have been an important source of political concern across countries for decades (Adams, 1968). The fear of the 'brain drain' and its depleting consequences -loss of talent, expertise and its corresponding scientific and economic investments and results- was first documented in the Sixties when massive emigrations of German and British scientists to the United States took place (Balmer et al, 2009). Later, in the Seventies and Eighties, the same concern emerged in the face of migrations from developing countries' in Latin America and Asia to the United States and Europe (Brandi, 2006). The study of this phenomenon, linked to a traditional braindrain vision of mobility as one-way flow of expertise between origin and destination (Salt, 1997), mainly considered the emigration experiences (Meyer and Brawn, 1999; Saxenian, 2005). Currently, although there is no comprehensive recording of researcher flows and movements (MORE, 2010), there is an increasing sense that significant emigration of scientists and the highly skilled is occurring from countries affected by the economic recession, due to the search for better labour opportunities. Spain is an example of this new professional emigration. According to some reports and media, the strong cuts in public R\&D funding and the lack of career perspectives in the country are increasing the emigration rate among Spanish researchers - and apparently without prospects of return (Aceituno, 2013). The recent economic crisis has thus reopened the brain drain threat for certain countries, like Spain, that have invested considerably in highly skilled human capital in recent decades. 
PREPRINT version

This paper has been published in Science, Technology and Society, Vol. 20(3), 322-348

In spite of the initial negative consequences of the brain drain, there are also different phenomena that can counteract its effects, as recent history has shown (Gaillard and Gaillard, 1999). First, the return of expatriated scientists to their home country, or 'reverse brain drain', has been documented as flows of highly skilled Asian personnel returned from (mainly) the United States to their countries including Korea, India and China (Krishna and Khadria 1997; Saxenian, 2005; Song, 1997). Later, with the revolution in the information and communication technologies and the production of human capital movements in 'all-directions' (Mahroum, 2000: 168), a new paradigm started to consider both scientific migration and international mobility experiences. In this new context, the so-called 'brain circulation paradigm' suggests a changing logic of migrations and mobility, conceiving them as processes of geographical circulation of people and ideas and stressing the importance of the interpersonal relations among the scientists of the diasporas and between them and the national research communities through the 'return and diaspora options' (Gaillard and Gaillard, 1997, 1998).

In this paradigm, collaboration links and their corresponding 'comings and goings' are key phenomena characterising brain circulation regardless of the geographical location of individuals and/or the often limited temporal duration of research stays (Ackers, 2005; Laudel, 2005; Jöns, 2008). According to Ackers (2005), the impact of high skilled migration on knowledge transfer depends not only on 'who is moving' -his/her knowledge, skills and scientific networks- but also on the nature of the mobility -the direction of flows, their frequency, duration, permanency and propensity to return. The return of researchers abroad, the duration of their stay and their research collaborations appear then as three important elements underwriting the circulation of knowledge. 
PREPRINT version

This paper has been published in Science, Technology and Society, Vol. 20(3), 322-348

This paper focuses on these three elements (research collaborations, the duration of international research visits, and return to the home country) and analyses their relationships using a sample of 189 mobile Spanish scientific researchers. This mobile research population are all applicants to the Spanish Ramón y Cajal (RyC) program, which funds five-year Fellowships to work in Spanish public sector research organizations. A pre-condition for applying to the RyC program has historically been work experience in a foreign institution of at least 24 months duration ${ }^{1}$. First, the paper studies the types of collaborations these mobile researchers have been involved in and whether these collaboration types are associated with international stays of different durations. Second, the paper analyses whether the duration abroad and the collaboration types affect the probability of return to Spain. In the current Spanish research context, where brain drain and brain circulation dynamics seem to coexist, the exploration of these questions can help us understand the way these processes are unfolding and disentangle these phenomena to some extent. The article proceeds as follows: Section 2 presents the literature review and our research hypotheses; Section 3 provides an overview of the Spanish research context; Section 4 describes the method and approach, Section 5 describes our results and Section 6 discusses the main findings.

\section{Previous research and hypotheses}

2.1. Collaborations and the duration of research stays

The brain circulation approach acknowledges the 'multiform' character of mobility (Gaillard and Gaillard, 1998) and the importance of considering mobility characteristics to assess its effects on knowledge circulation. For instance, if mobility is long-term or 
PREPRINT version

This paper has been published in Science, Technology and Society, Vol. 20(3), 322-348

permanent and is not compensated by collaborations and knowledge flows with the home-country, then it can be considered a loss. Yet, if mobility implies short stays abroad and creates transnational collaborations that include the home-country, then it can be considered a gain (Casey et al, 2001, Ackers, 2005). International collaborations and the duration of research stays are thus two important characteristics of mobility that can shape knowledge circulation.

Contemporary science is often characterised as being done through large-scale collaborations that include the participation of multiple research teams and inter-linked projects and the flourishing of co-authorship networks that are often interdisciplinary and transnational (Gibbons et al, 1994). The international mobility of researchers is thus closely integrated with such collaboration and co-authorship networks. As a result, the international mobility of researchers has increasingly taken on a networked character (Jöns, 2009) and may be frequently channelled by these collaborative connections. For instance, some studies find that mentors and senior colleagues appear as highly influential actors in shaping researchers' mobility decisions (Melin, 2004) and themselves constitute important 'pull factors' (Jöns, 2007; Ackers, 2005; Meyer, 2001; Mahroum, 2000). In turn, mobility can shape the researcher's collaboration network, reconfigurating their structure.

The 'face to face' interaction that international mobility entails facilitates the building of social capital (Libermann and Wolf, 1997; Wagner, 2005). As some studies observe, mobile researchers tend to create new scientific collaborations and international links in the host countries (Van de Sande et al, 2005; De Filippo et al, 2007; for example), some of which remain important for subsequent international mobilities (Jöns, 2009; Woolley 
et al, 2008). There is evidence that shows that mobile researchers have more and better international collaborations compared to non-mobile researchers (Franzonni et al, 2012; De Filippo et al, 2009). There is also evidence that mobile researchers tend to maintain collaboration links with their country of origin during the mobility experience (Fontes, 2007), and with the recipient country after the return (Jonkers and Tijssen, 2008). The maintenance of the collaboration patterns can impact on both the researchers' return and productivity (Baruffaldi and Landoni, 2012). In addition, as a result of the mobility, the researcher may act as a 'bridge' between their prior collaborators and those developed in the host country. This can also occur when the mobile researcher 'inherits' the scientific networks of supervisors and senior colleagues (Melin, 2004), becoming included in these international networks in their own right (Ackers et al, 2008).

However, the process of reconfiguration of the collaboration network that mobility entails may also imply the loss of collaboration links. A survey of the mobility patterns and career paths of European researchers (MORE, 2010) ${ }^{2}$ found that some respondents reported that mobility lead to a loss of contacts with colleagues and other partners in their home country. This had a negative impact on their career progression and complicated the return home (MORE, 2010). Other studies have found that mobility does not enhance the prospect of career progress in the home country (Cruz-Castro et al, 2006; Marinelli et al, 2014).

Based on these considerations, in this paper we explore the potential relationship between the duration of the stay abroad and the structure of the mobile researcher's collaboration network. More precisely, we hypothesise that researchers who go on 
PREPRINT version

This paper has been published in Science, Technology and Society, Vol. 20(3), 322-348

longer stays abroad initiate more collaboration links with the host country than researchers that spend shorter periods of time abroad (Hypothesis 1).

\subsection{Return}

The study of the factors that condition and determine the return of emigrated researchers to their home country has been tackled from different approaches. The neoclassical economic approach has mainly focused on the effect of wage differentials between the home and the host countries (Cassarino, 2004; Throm and Holm-Nielsen, 2006). In this context return is the result of a failure in such a calculation or the reversal in such a differential. In contrast, the more sociological 'transnationalism approach' considers the researchers' linkages with the home country as very important factors influencing the return. These include the 'national identity' and 'natural gravity towards home' (Throm and Holm-Nielsen, 2006) that push researchers to form 'scientific diasporas' (Meyer and Brown, 1999) and maintain strong links with the home country.

It is interesting in this respect to consider the distinction made by Casey et al. (2001), who studied the factors that condition the return to Europe of young researchers in the areas of Information and Communications Technologies and Biotechnology, after a period spent abroad. This study distinguishes two main groups of factors that condition the non-return of researchers. Reputation and home collaboration linkages are related to becoming 'locked out' of the home system, whereas the length of the stay abroad is more connected to the possibility of being 'locked in' to the host system. Being 'locked out' can arise when the individual abroad is not able to establish scientific prestige and when he or she does not keep in touch with the research community back at home. If 
PREPRINT version

This paper has been published in Science, Technology and Society, Vol. 20(3), 322-348

researchers do not reach a high international reputation during the period abroad, for instance by not publishing in reputable journals or going to institutions of weak prestige, their attractiveness to the home research system drops dramatically and they can experience a difficult return. Also, if researchers abroad do not keep home-country ties, they may lose touch with the requirements, informal and tacit in many cases, for reentry into the home system. Researchers can also become 'locked in' to the host system. This mainly occurs as time passes in the host country and the personal and professional ties and commitments of the researchers become stronger and more difficult to replicate in the home country.

A study by Baruffaldi and Landoni (2012) of a sample of researchers abroad (497 foreign researchers in Italy and Portugal) found that the probability of return is increased by the presence of home country linkages and decreases with the duration of the stay in the host country. Fontes (2007) and Van de Sande et al. (2005) find that most researchers, who return, do so via their organisation of origin. These studies thus also suggest that the maintenance of collaboration links with the home organisation can facilitate the return. As Casey et al. (2001) point out, if the researcher goes away having somewhere to return to, the return path is secure. Consistent with these findings, the MORE report (2010), found that losing home collaborators can be a barrier to return.

There is also empirical evidence regarding the link between the duration of mobility abroad and the return. According to the impact assessment report of the Marie Curie fellowships (Van de Sande et al, 2005), those on longer outgoing fellowships were less likely to return. Empirical findings seem then to support the idea that the likelihood of returning home is reduced as the length of the stay abroad increases. However, returning home is more likely in the presence of collaboration links with the country of origin. 
PREPRINT version

This paper has been published in Science, Technology and Society, Vol. 20(3), 322-348

Based on previous evidence, we thus hypothesise that the probability of return decreases as the time abroad increases (Hypothesis 2); and that the probability of return is lower for researchers with weaker collaboration links with the home country (Hypothesis 3).

\section{The mobility of Spanish researchers: setting the research background}

3.1. Mobility trends and available data

The historical trajectory of the Spanish research system is in some ways unique. The emergence of the system, characterised by the creation of modern scientific institutions in the first third of the $\mathrm{XX}^{\text {th }}$ Century, was abruptly interrupted by the Civil War (19361939) and the dictatorship (1939-1975), which subjugated scientific knowledge and institutions (Herreros-Chandro, 2013). The Spanish scientific, intellectual and artistic exile that followed the establishment of the dictatorship and the purging of academic institutions had long-lasting consequences. According to Herreros-Chandro (2013: 10) this was the last and worst process of systematic destruction faced by the Spanish science system until the recent, and ongoing, economic crisis. Concerns about the loss of scientific and intellectual human capital and the brain drain have characterised the Spanish research system in recent decades and have been exacerbated by shrinking public funding of scientific activity as a consequence of the financial crisis.

The Spanish research system as we know it today is a result of the efforts undertaken after the return to democracy in 1975, the incorporation of Spain to the European Community in 1986, and the approval of the first 'Law of Science' ${ }^{3}$ in the same year. The research system has developed considerably in the last decades but still lags behind 
PREPRINT version

This paper has been published in Science, Technology and Society, Vol. 20(3), 322-348

the European average in terms of its main indicators (EC, 2014) and a stable policy framework (OECD, 2006; Fernandez-Zubieta, 2014, ERAC, 2014). Both human and financial resources devoted to the research system have suffered dramatically the consequences of the recent economic crisis. According to Eurostat (Science and Technology Indicators, $2014^{4}$ ), in 2011 , R\&D intensity in Spain (R\&D expenditure as a percentage of GDP) was 1.33 per cent (EUR 14,184.3 million - approx. USD 19,645.2 million ${ }^{5}$ ), well below the EU-27 average (2.03per cent) and the EU goal of 3 per cent set by the European Strategy 2020 (EC, 2010). The trend of increased investment in government budget appropriations on research and development (GBAORD) starting in 1995, was interrupted in 2009 and registered strong cuts in the following years. According to the statistical data of the Spanish Ministry of Economy and Competitiveness (MINECO), GBAORD was EUR 2,183.4 millions in 1995 (approx. USD 3,023.0 millions); 8,699.8 in 2009 (approx. USD 12.049,2 millions) and 7,252.3 in 2011 (USD 10,044.4 millions) (MINECO database, 2014 ${ }^{6}$ ). R\&D investment for 2012 was around EUR 13.4 millions (USD 18.5 millions), or 1.3 per cent of GDP (INE, 2014). A similar trend is observed in the research population. Between 2003 and 2010, the research population in Spain grew from 158,566 to 224,000 (head count) and then started to decline, registering 220,254 in 2011 (Eurostat, 2014). In that year, this population represented 0.95 per cent of the labor force in Spain, compared to 1.06 per cent in the EU27 (Eurostat, 2014). The increase in the population of researchers up until 2011 alleviated worries concerning their outflows and the potential brain drain. However, recent trends have exacerbated the debate on the Spanish brain drain and the lack of career opportunities for young researchers, which is highly visible in both the international and national media and in evaluation reports ${ }^{7}$. 
PREPRINT version

This paper has been published in Science, Technology and Society, Vol. 20(3), 322-348

The actual knowledge on outflows and inflows of the highly skilled in general, and researchers in particular, is very scarce in Spain. The statistics on the participation of foreign students in tertiary education show an increasing rate of foreign students since 2008 , from 2 per cent $(36,089$ students) to 5.5 per cent $(107,405)$ in 2011 , especially in the Engineering, manufacturing and construction academic fields (Eurostat, 2014). Although the total number of Spanish nationals abroad has decreased by 11.5 per cent from 1995 to $2010(699,291$ to 618,773$)$, the number of these with high levels of education has increased by 88.8 per cent in the same period $(94,062$ to 177,611$)$ (Brïcker et al., 2013). The percentage of the highly educated among the total Spanish abroad has risen from 13.45 per cent in 1995 to 28.7 per cent in 2010 (Brücker et al., 2013). ${ }^{8}$ The European Survey on Career Development of Doctoral Holders (CDDH) provides some information on mobility of researchers residing in Spain at the time of the survey. CDDH data for 2009 (INE, 2014) show that 22 per cent of surveyed PhDs spent more than three months working abroad during the reference period (2000-2009). Researchers reported the main motivation for carrying out research visits outside Spain was 'academic reasons' (58.5 per cent). In contrast, the main reason for visiting Spain for more than three months among those coming from abroad in the same period (either national or foreign researchers) was 'personal and family reasons' (37.7 per cent). Academic reasons were only reported to be an attraction factor by 17.6 per cent, suggesting a relatively weak scientific attraction capacity of the Spanish research system.

This weak scientific attraction capacity is acknowledged by other sources, such as the INNOVACEFF report ${ }^{9}$, based on a periodic survey addressed to young Spanish researchers since 2006 by a consortium of academic and scientific organisations ${ }^{10}$. This 
PREPRINT version

This paper has been published in Science, Technology and Society, Vol. 20(3), 322-348

report confirms how negative perceptions concerning the Spanish research system are encouraging the emigration intentions of young researchers. In 2013, 546 researchers residing in Spain and 227 working abroad responded to the survey. A synthetic index calculated on the basis of the survey data that shows the confidence of researchers in the science system where they work, finds an average confidence level of 40/100 for researchers residing in Spain compared with 60/100 for those working abroad. According to the latest available report (Aceituno, 2013), 82.5 per cent of researchers working in Spain state their intention to move abroad. Plans to move are imminent in 12.8 per cent of cases. At the same time, 79.7 per cent of Spanish researchers working abroad find the prospect of return to Spain unlikely. Since the first edition of this report in 2006, the confidence level in the Spanish R\&D System has declined substantially, suggesting a possible exacerbation of the brain drain problem. Public policy has therefore a major role to play to counteract the declining trends. The following subsection briefly describes the major policy tools that target research human resources and their mobility in Spain.

3.2. Public policies supporting the development of human resources for research

Current Spanish R\&D policy is characterised by a multilevel governance system (Edler and Kuhlmann, 2003), in which national policies co-exist with diverse regional and European initiatives. Spain is formed by seventeen autonomous communities, which have their own regional R\&D policy. One goal of the recently approved Science, Technology and Innovation Law (14/2011) is to coordinate this diversity of policies and policy levels. Despite the increasing influence of regional administrations on the Spanish R\&D system (Sanz-Menéndez and Cruz-Castro, 2005), national policies are 
PREPRINT version

This paper has been published in Science, Technology and Society, Vol. 20(3), 322-348

still the most important in terms of public budget. In 2012, 72.3 per cent of the total budget for R\&D (EUR 8,840 millions - USD 12,243.4 millions), was funded by the state and 27.7 per cent by the regional administrations (MINECO, 2013a). We therefore only outline briefly public policies at the state level that are targeted at promoting the development of the research workforce and at counteracting the effects of the perceived brain drain.

The promotion, integration and employability of research talent is one of the four main goals set by the Science, Technology and Innovation Strategy (2013-2020), the document that provides the general policy framework for R\&D in Spain. The strategy sets the rationale, objectives and indicators and it is implemented through the Spanish State Plan for Scientific and Technical Research and Innovation (2013-2016) by setting its priorities, programs, coordination mechanisms, costs and sources of funding. The plan is executed through annual programs of specific actions. Programs are in turn divided into sub-programs, which are articulated around various competitive calls that channel the allocation of public R\&D funds. Human resources and their mobility play a relevant role in this configuration. This also includes the attraction and integration of non-national researchers into the Spanish research system (MINECO, 2013b).

An important funding effort was devoted to the training, development and attraction of researchers during the decade of the $2000{ }^{\prime}{ }^{11}$. In the current R\&D national plan (20132016), these initiatives are framed by the 'national program for the promotion, integration and employability of talent' and in the previous plan (2008-2011) by the 'human resources instrumental line of action'. In 2008, the funding for human resources programs was EUR 395.5 millions (USD 547.7 millions), which represented around 11 
PREPRINT version

This paper has been published in Science, Technology and Society, Vol. 20(3), 322-348

per cent of the total annual national R\&D budget. This amount has decreased substantially over the years and in 2012 was reduced to EUR 161.8 millions (USD 224.1 millions). The funding for the support of research human resources is classified into Training, Hiring and Mobility programs. The training national program funds predoctoral and post-doctoral training contracts and short research visits to foreign organisations; the national hiring program funds contracts for the integration of R\&D personnel in research centres, universities and the productive sector, and the mobility program provides support for academics and researchers to organise research visits in foreign organisations. Since 2008, with the exception of 2012 when Spanish science suffered a dramatic budgetary cut,- the hiring program has absorbed the largest part of available public funds devoted to human resources, followed by the training and mobility programs (table 1).

\section{[Table 1]}

There are three main programs regarding mobility and the return of Spanish nationals from abroad: the Ramón y Cajal (RyC), the Juan de la Cierva and the JAE program. The Ramón y Cajal program, which this paper studies, is the 'star program' of the 'national hiring' policy line. The Juan de la Cierva was the equivalent program for young postdoctoral researchers. The JAE program is a central program for training and hiring the main Spanish public research centre (Spanish National Research Council- CSIC) previously called I3P.

The RyC program was launched by the Spanish Ministry of Education in 2001 and is currently managed by the Ministry of Economy and Competitiveness. The program 
PREPRINT version

This paper has been published in Science, Technology and Society, Vol. 20(3), 322-348

provides competitive financial support to Spanish R\&D organisations for hiring researchers during five years. In 2011, it had a budget of EUR 45.9 millions (USD 63.6 millions) rising to EUR 54 millions in 2012 (USD 74.8 millions). The aim of the program is to facilitate researchers' career stabilization in Spain and to promote their independence and leadership. One of its main goals originally was also the recruitment of foreign researchers and the attraction back of Spanish nationals working abroad. In fact, it may be argued that the RyC program is the most important public policy tool aimed at channelling the return of Spanish expatriate researchers. Candidates to the RyC program are selected through a competitive evaluation process and are required to have a $\mathrm{PhD}$, to have obtained it at the most ten years before the call date and to have an extended international mobility experience ${ }^{12}$. As a result, average RyC candidates are in their mid-thirties, have around fifteen years of professional experience and an international profile. To date, the RyC program has been quite successful in incorporating highly qualified researchers into the system and in attracting back Spanish researchers working abroad. According to a recent survey conducted by the Ministry and answered by 3,946 researchers that applied to the RyC program over the period 2001-2010, 84.1 per cent of the applicants were Spanish nationals and almost 25 per cent lived abroad at the time they applied. An important reported reason for applying to the program was their wish to return or come to Spain (MICINN, 2011). During the period covered by our study (2005-2009), around 30 per cent of researchers funded by the program each year were residing abroad when they applied $(35,31,34,32$ and 28 per cent respectively).

The program seems to have failed, however, to provide professional stability to the funded researchers at the end of their five-year RyC contract. In November 2012, the 
PREPRINT version

This paper has been published in Science, Technology and Society, Vol. 20(3), 322-348

National Association of RyC Fellows (ANIRC) made public their concern about a potential drain of talent due to the incapacity of the public system to provide the tenuretrack positions initially promised to RyC fellows at the end of their initial five-year contract $^{13}$. In August 2013, an open letter published in the national press and addressed to Spain's prime minister by a former RyC fellow 'packing her bags' to work at NASA, was also widely diffused internationally (The Guardian, August $28^{\text {th }}$ ).

Given the eligibility criteria of the program, the population of RyC candidates is considered to be highly productive, internationally connected and mobile, compared to the national average. Considering the general shortage of data on mobility of researchers and its impact, the possibility to access the information contained in the curricula vitae of candidates to the program provided a unique opportunity to study certain dynamics of mobility and collaboration, as well as to address the dynamics of return to Spain to some extent. The following section describes in detail the characteristics of the data and methodologies used to address our research hypotheses.

\section{Methods and data}

4.1. Data, population and sample

The study sample is drawn from researchers who applied to the RyC program in the period 2005-2009 (8,201 applicants). All candidates to the program during the studied period had been 'internationally mobile', having spent at least 24 months doing research abroad. A selection bias operates regarding the study of return, considering that all 
PREPRINT version

This paper has been published in Science, Technology and Society, Vol. 20(3), 322-348

applicants living abroad wished to return to Spain to take up the Fellowship if successful. This limits the generalizability of our results as will be discussed later.

Our study includes only researchers who are Spanish nationals and who obtained both their undergraduate degree and their $\mathrm{PhD}$ in a Spanish university. Since our main interest is to study research collaborations that may somehow be associated with a specific mobility, we do not take into account candidates that are either foreign, or trained abroad as their international networks at the time of the application to the Program would be influenced by their past international work and mobility experience. Candidates to the RyC Program are classified into 24 research fields, out of which we selected three for our study: Physics (P) ${ }^{14}$, Agricultural Science (AS) and Molecular Biology (MB). These fields are among those receiving the highest number of applications ${ }^{15}$ and, unlike other fields, their definition within the program did not change over the period under study ${ }^{16}$. As a consequence of the RyC mobility requirements all researchers included have also undertaken a single post-doctoral research stay of at least 24 months (two years or more) in a foreign country. This condition was also used for analytical purposess to distinguish between two temporal career stages, before and during the mobility, and to avoid the effect of multiple mobility experiences.

The final sample is composed of 189 researchers, 31.4 per cent from Physics, 27.2 per cent from Agriculture and 41.5 per cent from Molecular Biology (see table $2^{17}$ ). This sample was drawn from a population of 1503 Spanish applicants, 472 of which came from Physics, 408 from Agriculture and 623 from Molecular Biology.

\section{[Table 2]}


PREPRINT version

This paper has been published in Science, Technology and Society, Vol. 20(3), 322-348

Our empirical analysis is based on a set of variables that were built out of the information contained in the curricula vitae of the studied candidates. Curriculum vitae analysis (CV analysis) is acknowledged to be a valuable method to assess individual academic trajectories and to capture the complex nature of mobility and its connections with the formation and transformation of collaboration networks (Cañibano and Bozeman, 2009). All candidates to the RyC program must submit a standardised full version of their CV (available in pdf and word format), which is stored at the Ministry of Education. Access to curricular information was granted to our research team by the Ministry under a confidentiality agreement. This allowed us to collect the same information for each applicant and to code CVs manually. All CVs were coded by the same person, which assures coding consistency and avoids inter-coder reliability problems (Dietz, 2004).

Apart from general data about each candidate including age, gender or residency the construction of variables relied on the coding of information from three sections of the $\mathrm{CV}$ : i) research stays abroad, ii) participation in competitive research projects and iii) publications. As described earlier, sampled candidates only reported one post-doctoral 'stay abroad' of at least 24 months of duration. The CV collects information on starting and ending dates for these stays; name of recipient organization, destination and country. We also use this information to link the participation in research projects and co-authourships in publications with the mobility stay.

We consider participation in research projects as a vehicle for receiving training and mentoring from the project's Principal Investigator (PI), and for establishing 
PREPRINT version

This paper has been published in Science, Technology and Society, Vol. 20(3), 322-348

collaboration partnerships with researchers from the country that is hosting the mobility. The information used concerning projects was starting and ending dates, names of participating organizations, name of the Principal Investigator and funding institution. To construct the analytical variables, we made the distinction between projects developed in Spain (national projects) and those developed in the country hosting the previously coded mobility (international projects). Participation in research projects developed in third countries was not considered. We were interested in identifying Principal Investigators who might have played a role in either channelling the mobility or mentoring the researchers, both before and during their period abroad. We summarise these roles through the labels 'Host PI' and 'Home PI'. To identify Host PIs we selected PIs of projects that were developed in the country hosting the mobility during the mobility period ${ }^{18}$. 'Home PIs' are PIs of projects developed before the mobility period and includes PIs based in both Spain (most of the cases) and the host country.

The CV section on publications was used to build variables regarding co-authorships, as additional measures of collaborations. We were particularly interested in distinguishing co-authorships that might have resulted from the mobility experience. We applied a lag of one year in the coding of co-authorships. For example, for an international stay taking place from January 2002 to December 2004, a publication dated in 2002 would be assigned to the period before the mobility, while a publication dated in 2005 would be assigned to the period during the mobility. Co-authors of publications assigned to the period before the mobility are considered as previous coauthors and co-authors of publications assigned to the period during the mobility are considered as new co-authors. 
PREPRINT version

This paper has been published in Science, Technology and Society, Vol. 20(3), 322-348

\subsection{Variables}

The analysis of the collaboration dynamics and the study of return required the additional design of a set of variables as described bellow.

Return is the main dependent variable of the model designed to analyse the factors that might have influenced on the eventual return of the applicant researcher. This is a dichotomous variable that informs about whether the researcher has returned from his stay abroad. It has been coded according to the residence country of the researcher at the time of the application -Spain or other-. It takes the value 1 when the researcher has returned to Spain and 0 otherwise.

The main independent variables of the model are Duration of the international stay and four types of collaborations. Duration classifies stays abroad according to two categories. 'Short' stays are those lasting for a period of two years (the variable takes the value 0) and 'long' stays are those lasting for more than two years (the variable takes the value 1$)$.

Types of collaboration included are formal participation in research projects (A.1 Research projects) and co-authorships (B.1 Mobility Co-authorship, B.2 International Mentoring Co-authorship and B.3 PI co-authorship),

\section{A. Research Projects}

A.1. Research projects: Formal participation in research projects during the stay abroad is considered as a fist type of collaboration. This type of collaboration includes two dummy variables: the participation of the mobile researcher in national research projects during the mobility (yes/no) and in international research projects during the same period (yes/no).

\section{B. Co-authorships:}


PREPRINT version

This paper has been published in Science, Technology and Society, Vol. 20(3), 322-348

B.1. Mobility Co-authorship: This indicator attempts to capture co-authorships that can somehow be associated with the mobility period. As pointed out above, a time lag of one year is applied. We distinguish between 'previous' co-authors (they have already co-published with the researcher before the mobility) and 'new' co-authors (otherwise). This co-authorship type includes two dummy variables: co-authorship with previous co-authors during the mobility (yes/no) and co-authorship with new co-authors during the same period (yes/no).

B.2. International Mentoring Co-authorship: This type of co-authorship attempts to capture the role that international mentoring might play in channelling both the outgoing and the return mobility. It refers to co-authorship collaboration between the researcher and the Host PI as defined above, both before and during the stay abroad. It includes two dummy variables: co-authorship between the mobile researcher and the host PI before the mobility (yes/no) and during the mobility (yes/no).

B.3. PI co-authorship: This type of co-authorship attempts to capture the existence of networks that might play a role in channelling both the outgoing and the return mobility of the researcher. It considers co-authorships between home and host PIs. It includes two dummy variables: co-authorship between home and host PIs before the researcher's mobility (yes/no) and during the same period (yes/no).

We then consider that the mobility experience may induce three different possible dynamics that may apply to any of the above collaboration types. Each type of collaboration dynamics corresponds to a mutually exclusive combination of the dummy variables' values (table 3). The three considered types of dynamics are:

\section{Collaboration dynamics:}


1) No collaboration: refers to the failure to commence collaboration or the extinction of a previous collaboration during the mobility period. For example, if we consider 'International Mentoring Co-authorship', researchers that have neither co-published with a host PI before nor during the international stay will be in this category. So will researchers that co-published before, but not during, the international stay.

2) Initiating collaboration: refers to initiation of collaboration during the mobility period. For example, if we consider 'International Mentoring Co-authorship', researchers that did not co-publish with a host PI before their stay abroad but do so during that period will be in this category. If we consider 'Mobility Co-authorship' all researchers registering 'new' international co-authors will be registered in this category.

3) Maintaining collaborations: refers to the maintenance of pre-existing national or international collaboration during the mobility period. This indicator captures the durability or persistence of collaborations through time, taking into account the context of a changed geographic location. For example, researchers that co-publish with a host PI before and during their international stay will be in this category. So will researchers that publish with new co-authors during the mobility and keep copublishing with 'previous' co-authors during the mobility.

\section{[Table 3]}

Finally, the model includes several academic and demographic control variables: age, experience, precocity, publications, returning financial support, outgoing financial support, gender and discipline. Age is a continuous variable that takes the age of the researcher when the data was collected (1/10/2010). Experience is a continuous variable 
PREPRINT version

This paper has been published in Science, Technology and Society, Vol. 20(3), 322-348

that measures the time lag between the $\mathrm{PhD}$ award and 1/10/2010. Precocity is a dummy variable that takes the value of 1 if the researcher finished his/her $\mathrm{PhD}$. before the age of 29. This variable aims at being a proxy for the ability of the researcher. This fixed effect proxy tries to address the problem of unobserved individual heterogeneity (Heckman, 1979). Although limited, the underlying assumption is that the researcher that finishes their $\mathrm{PhD}$ early would be more attractive in the labour market. Publications is a variable that considers the annual number of publications published by the researcher during the stay abroad. This variable aims at being a proxy for researchers' ability to establish scientific prestige during the period abroad, which can make them attractive to the home country and may facilitate their return (Casey et al 2001). Returning financial support is a dummy variable that takes the value of 1 if the researcher return has been granted with financial support from a targeted public program (e.g. Juan de la Cierva, JAE Program or I3P). Financial support is a categorical variable that considers whether the researcher had financial support for their research stay abroad and if these funds were from national or international organisations (National, International and Other) ${ }^{19}$. Gender is a dummy variable that takes the value of 1 if the researcher is a woman and 0 for a man. Discipline is a categorical variable that takes into account the research field of the grant application (Physics, Agriculture and Molecular Biology). It aims at capture fixed field effects.

\subsection{The model}

We apply logistic regression (Greene, 2003) to study the effect of the duration of mobility and the type of collaborations linked to the mobility on the probability of the return of the researcher. Logistic regressions are suited to analyse binary outcomes, such 
as ours. Our dependent variable, Return, takes the value of 1 if the researcher has returned to Spain and 0 otherwise.

The dependent variable, return to Spain, is binary and can be formalised as follows:

$$
E_{i}=\begin{array}{ll}
1 & \text { if the individual has return to Spain } \\
0 & \text { otherwise }
\end{array}
$$

To explain it, we use a logit model:

$$
p_{i}=\operatorname{Pr}\left[E_{i}=1 \mid X_{i}\right]=\frac{\exp \left(\beta_{0}+\beta_{1} X_{i}\right)}{1+\exp \left(\beta_{0}+\beta_{1} X_{i}\right)}
$$

where $\mathrm{Xi}$ is a set of explanatory variables.

\section{Results}

\subsection{Descriptive statistics}

Table 4 shows the distribution of frequencies in our sample according to the destination and duration of the international stay. A total of 46.6 per cent of the researchers had returned to Spain at the time of their application. The majority of the sample (65.9 per cent) report stays abroad longer than two years. We see that the US and the UK are the most attractive destinations, having hosted 35.3 per cent and 24.1 per cent of the sample respectively, which coincides with results from previous studies on Spanish researchers (De Filippo et al, 2008; Aceituno, 2013). These countries seem to be even more attractive for longer visits than for short ones. Germany, France, Italy and the Netherlands also appear as important destination countries. Researchers with shorter international stays show a greater variety of country destinations. 
PREPRINT version

This paper has been published in Science, Technology and Society, Vol. 20(3), 322-348

\section{[Table 4]}

Tables 5 and 6 show the descriptive statistics concerning the variables defined in the previous section. As described earlier, variables concerning the types of collaborations include research projects and co-authorships (Mobility co-authorships, International mentoring co-authorships and PI co-authorships) and are grouped in three categories according to 'collaboration dynamics'. Concerning collaboration in research projects, the three categories of collaboration dynamics show the same frequency values (around 33 per cent). Researchers are evenly divided between those not involved in a research project with the host country during the mobility (no collaboration), those that start being involved in a research project with the host country during the mobility (initiating collaboration), and those who are involved in research projects with both the host and the home countries during the mobility (maintaining).

In contrast, patterns of co-authorships show a more uneven distribution across dynamics of collaboration. Most researchers (75.5 per cent) 'maintain' their co-authorship network during their mobility. Researchers are able to start publishing with new coauthors and to keep publishing with previous ones. This result appears to support the idea that mobility facilitates the development of a network of co-authors (De Filippo et al, 2009; Franzonni et al, 2012; Woolley et al, 2008). In addition, most researchers (53.8 per cent) register new co-publications with a Host PI during the mobility. A small proportion of researchers published with a Host PI also before the mobility (8.5 per cent) (maintaining), further supporting the idea that 'new' international mentoring collaborations are built during the mobility. When checking the co-publishing practice 
PREPRINT version

This paper has been published in Science, Technology and Society, Vol. 20(3), 322-348

between home a host PIs (PI co-authorship), we see that co-authorships between them is a rare practice that only includes 11.8 per cent of researchers in the sample.

In terms of the sample characteristics, the average age is 38 years, with a range from 31 to 56 years inclusive. The average applicant has 9 years of post-doctoral research experience, ranging from 5 to 15 years. A total of 52.9 per cent researchers finished their $\mathrm{PhD}$ before the age of 29. Researchers publish an average of 0.8 publications annually. A total of 18.3 per cent of researcher had financial support for their comingback to Spain. The majority of researchers obtained financial support for their outgoing international mobility, either through national (30.5 per cent) or international (24.2 per cent) fellowships. A total of 43.8 per cent of the researchers in the sample are women.

\section{[Table 5]}

Table 6 presents some descriptive indicators taking into account the relationship between the duration of international stays and the different types of collaborations. The dynamics of collaboration in research projects seems to be affected by the duration of the stay. Researchers with longer stays tend to initiate collaborations more frequently (42.4 per cent of cases) than those with shorter stays (20 per cent). In contrast, 'no collaboration' is more frequent among researchers with long stays (44.2 per cent) compared to those with shorter stays (23.9 per cent).

Regarding the dynamics of co-authorship during the mobility period, we find that researchers with long stays show lower frequency of 'no collaboration' (6.1 per cent), compared to those with longer stays (13.2 per cent). The initiation of collaboration is in 
PREPRINT version

This paper has been published in Science, Technology and Society, Vol. 20(3), 322-348

turn more frequent among those with long stays (17.2 per cent compared to 13.7 per cent). A similar pattern is shown by the collaboration type 'international mentoring coauthorships'. Most researchers with long stays 'initiate' this type of collaboration during their stay (63.3 per cent), while most researchers with short stays tend to have a "no collaboration' outcome (53.6 per cent) that is, they either did not register international mentoring co-authorships or they lost them during the stay.

\section{[Table 6]}

Co-authorship between project's PIs is a rather rare practice. However, researchers with short stays more often conform to a 'maintaining' dynamics of collaborating through PI co-authorships (7.4 per cent compared to 5.2 per cent), while researchers with long stays tend to initiate more often ( 7.7 per cent compared to 2.5 per cent).

The relationship between the length of time passed in the host country (duration) and the types of collaborations is significant when we consider those developed through research projects and through co-authorships with the host PI (international mentoring). A test of homogeneity of proportions (equivalent to a test of independence for a twoway contingence table) confirms that there is a significant difference between the duration of the stays among the three collaboration dynamics established through research projects and through international mentoring $(\mathrm{F}(2,375.94)=5.8944 \mathrm{P}=0.003$ and $\mathrm{F}(2,375.97)=6.5285 \mathrm{P}=0.0016$ respectively $).{ }^{20}$ Regarding the other types of collaborations (mobility co-authorship and the PIs co-authorship), the proportion of the different categories does not change significantly comparing long and short international stays, as confirmed by non-significant homogeneity test of proportions. 
PREPRINT version

This paper has been published in Science, Technology and Society, Vol. 20(3), 322-348

Therefore, it could be said that longer stays abroad are connected to greater frequencies of initiating new collaborations through research projects and co-authorships with host PIs, while shorter stays are connected to a greater extent to no collaborations.

5.2. Multivariate analysis

Table 7 displays the results of the logit regression. The model is significant with a Pseudo R2 of 0.442 (McFadden's R2). The results show that duration has a negative and significant effect on the return of researchers. This indicates that researchers with longer international stays are less likely to be residing in Spain at the time of the RyC application submission. This result is in line with previous findings showing a negative relationship between the duration of the time spent abroad and the probability of return to the home country (Baruffaldi and Landoni, 2012).

According to the model, the only type of collaboration that has a significant relationship on the probability of return is 'PI co-authorships'. Co-authorship between PIs has a significant negative effect on the likelihood of return. Links developed through 'research projects' have a positive but insignificant effect and the collaboration type 'mobility co-authorship' and 'international mentoring co-authorships' have a negative but non-significant effect on the probability of return. In sum, we find some indication that collaborations showing the existence or formation of more 'established networks' the ones that involve new co-authorships between researchers in host and the sending countries- have a negative impact on the probability of return. 
PREPRINT version

This paper has been published in Science, Technology and Society, Vol. 20(3), 322-348

Regarding the control variables, the strongest, positive and significant variable is 'Returning financial support', indicating that public support mechanisms for the hiring of young researchers by Spanish institutions increases considerably the likelihood of coming-back to Spain. 'Age' shows a negative and significant coefficient suggesting younger researchers are more likely to return. Professional 'experience' shows a positive and significant association, indicating that more experienced researchers have a greater likelihood of coming back to Spain. 'Precocity' shows a negative and significant impact, which implies that early completion of the doctorate decreases the likelihood of return to Spain.

\section{[Table 7]}

\section{Summary and discussion of results}

Concerns about the loss of scientific and intellectual human capital in Spain have been exacerbated as a consequence of the financial crisis and the reduction in public funding of scientific activity. Important budgetary efforts were made at the beginning of the 2000's to empower the human resources of the research system. This includes the launching of the Ramón y Cajal program in 2001, which provided the setting for this study. Spanish public policies for the promotion of researchers' international mobility have been framed by both a 'circulation' rationale and a 'brain gain' perspective. On the one hand, public entities provide funding for Spanish researchers to spend time abroad and for foreign researchers to come to Spain in the framework of post-doctoral fellowships, academic temporary exchanges and other arrangements. On the other hand, policy programs like the Ramón y Cajal have attempted to provide attractive conditions 
PREPRINT version

This paper has been published in Science, Technology and Society, Vol. 20(3), 322-348

for both foreigners and expatriate Spanish researchers to come/return to Spain for more extended periods of time.

Our results show that a majority of researchers in the sample start co-publishing with a host PI during the mobility period, which we termed 'international mentoring coauthorship'. According to our data, it appears that mobility facilitates this kind of collaboration relationship. Additionally, most researchers start co-publishing with new authors during their mobility period, whilst also keeping their previous co-authorship collaborations going (maintaining). In other words, researchers do not tend to lose prior links because of their mobility. In addition, we observe that co-publication between home and host PIs is a rather rare practice, both before and after the international stay abroad, which could be interpreted as an indicator that mobile researchers' new collaborations are built with some independence from their existing mentoring networks. Mobile researchers, then, appear from this perspective as relatively autonomous 'network builders' (Turpin et al, 2008) who expand and internationalise their collaboration ties as they move around the world, with corresponding positive effects on knowledge circulation.

The empirical analysis confirms the expected relationship between the duration of the mobility and collaboration dynamics. According to the results, researchers with longer stays tend to initiate new international mentoring co-authorships and collaboration in research projects in a greater proportion than researchers with shorter stays (Hypothesis 1). Longer stays seem to provide better opportunities to publish with a host PI and to participate in research projects in the recipient country. It seems therefore that the length 
PREPRINT version

This paper has been published in Science, Technology and Society, Vol. 20(3), 322-348

of the stay is an important factor enabling the integration of the researcher in the host organisation and country.

Regarding the dynamics of return, and in line with Baruffaldi and Landoni (2012), we find that longer stays abroad reduce the likelihood of return, which confirms Hypothesis 2. As Casey et al. (2001) point out, this result can be due to the fact that as researchers spend more time in the host country their personal and professional commitments are stronger - researchers put down roots in the recipient country and become 'locked in' to the host system. This is consistent with the finding that the increase in age decreases the likelihood of return. However, the negative relationship between the length of stay and the likelihood of return does not necessarily imply a loss of collaboration links with the home country, as pointed out above. As Throm and Holm-Nielsen (2006) remark a 'natural gravity towards home' remains among expatriate researchers and sending countries can take advantage of this to participate in transnational knowledge circulation processes.

We find a significant negative effect of co-authorship between principal investigators of projects run in the host and home countries. The likelihood of return decreases if PIs start co-publishing during the researcher's mobility. This 'integrative practice' could be signalling a stronger engagement of the mobile researcher in the host institution and could be seen as another evidence of being 'locked in' to the host country. Nevertheless, far from implying a loss of contact with the home country, this appears to be positive for the establishment of collaborations between home and host countries. It could also be indicative of a 'brokering' role for mobile researchers between their mentoring (home) and independent (host) research networks. 
PREPRINT version

This paper has been published in Science, Technology and Society, Vol. 20(3), 322-348

Contrary to our expectations we did not find evidence of other significant effects on the probability of return (Hypothesis 3). It appears that the initiation and maintenance of 'co-authorships' tends to reduce the likelihood of return, while the initiation or maintenance of 'participation in research projects' tend to increase the probability of return to the home country, when comparing to the 'no collaboration' dynamics. However, as these results are not statistically significant in our models these interpretations should be viewed with caution.

Public policies aimed at attracting young researchers appear to be crucial when explaining the return of Spanish abroad. Our results support the worrisome prospects of young researchers found in recent reports on the Spanish R\&D system (e.g. ERAC, 2014 and Fernández-Zubiteta, 2014). Young researchers have suffered considerably the consequences of recent budget cuts in R\&D (Fernández-Zubieta, 2014) delaying their taking up of a permanent position or pushing them to seek better career prospects abroad. Our results indicate that, if a young talented researcher stays abroad for a longer period, it is more difficult to return to Spain. Recent budget cuts in Spanish public R\&D programs could also reinforce the danger of Spain of suffering a brain-drain problem. Our results indicate that the most important variable determining the return of young talented researchers from abroad is receiving financial support for reintegration into the Spanish system. Budget cuts may well reduce the likelihood of return for young researchers who are currently abroad - a potential 'lost generation'. On the positive side, the same results indicate that these policy instruments appear to work and increasing funding might help to effectively reverse this negative trend. Having said that, as the ERAC report indicates, it might be necessary to restore a form of secure 
PREPRINT version

This paper has been published in Science, Technology and Society, Vol. 20(3), 322-348

career path for these researchers in order to address this 'most pressing problem' (ERAC, 2014: 5) of the Spanish R\&D system. However, an increase in the availability of public funds for the return of researchers abroad may only produce a patchwork solution unless such a measure is combined (and coordinated) with policies that can facilitate returning researchers' institutional reintegration into the Spanish research system.

\section{Acknowledgements}

The authors would like to thank the former Spanish Ministry for Science and Innovation (current Ministry for the Economy and Competitiveness) and the Sub-Directorate for the training and hiring of researchers for providing the necessary data to conduct this study. Ana Fernandez-Zubieta acknowledges financial support from the JAE-Doc 'Junta para la Ampliación de Estudios' Program that is co-financed by the European Social Structure Funds (SSF). The authors also wish to thank Richard Woolley for his careful reading of the paper and his useful comments.

\section{Notes}

\footnotetext{
${ }^{1}$ This requirement was dropped in 2013.

${ }^{2}$ The MORE project was promoted by the European Commision to study the mobility patterns and careers of the UE-27 researchers. In the framework of the project a survey was conducted to a sample of HEI researchers across the EU27 (4,538 validate answers). In this study, international mobility was defined as the physical movement of an individual researcher from one country to another country (into, out of or within the EU) either to a new employment position or for a research visit of at least three months duration.

${ }^{3}$ Ley 13/1986 de Fomento y Coordinación General de la Investigación Científica y Técnica. April, 14th.

${ }^{4}$ Last accessed June, 2014.

${ }^{5}$ Euro foreign excahnge reference rate of April 2014 (European Central Bank) 1EUR = 1.385 USD.
} 
PREPRINT version

This paper has been published in Science, Technology and Society, Vol. 20(3), 322-348

${ }^{6}$ http://www.idi.mineco.gob.es/stfls/MICINN/Investigacion/FICHEROS/Estadisticas_Indicadores/Credito s_Finales_ID_1995-2011_euros_corrientes.pdf

${ }^{7}$ See for example the following articles: 'Sigue la fuga de cerebros: España pierde a uno de los líderes mundiales de la investigación con células madre', El País, January 15 ${ }^{\text {th }}$, 2014. 'Dark clouds over Spanish Science', Science, June 14 ${ }^{\text {th }}, 2013$; 'Young Spanish scientists in limbo', Science Careers - Science; March 2 $2^{\text {nd }}, 2012$; 'Funding uncertainty strands Spain's young scientists', Nature, March 6 ${ }^{\text {th }}, 2012$. 'España se enfrenta a otra fuga de cerebros', Publico.es, February 2nd, 2012. See also ERAC (2014) and Fernandez-Zubieta (2014) as the most recent report pointing out this problem.

8 Calculations with data from the Institute for Employment Research (IAB) on Spanish migrants in 20 OECD countries. More recent data from other sources (e.g. OECD) was not available at the time of writing.

9 Latest edition available at: http://www.udima.es/es/resultados-de-estudio-innovacef-2013.html, last accessed June, 2014.

${ }^{10}$ The Distance Education University of Madrid (UDIMA), the Centre for Financial Studies (CEF), the Young Researchers' Association (FJI/Precarios), the Official College of Physicists and the associations of Spanish researchers in the UK and Germany.

${ }^{11}$ In spite of the considerable effort that has been made, some collectives condemn that the usual delays in the aids and the limited resources, aggravated by the crisis, do not still offer good conditions for developing a respectable research career in Spain (FJI, 2007; COSCE, 2005).

12 Between 2001 and 2012 the mobility requirement implied to either: 1) have worked abroad as a researcher during at least 24 months in $\mathrm{R} \& \mathrm{D}$ centres different from the RyC program host or 2) to have entirely studied the $\mathrm{PhD}$ in a foreign university. The last call of the program (2013) seems to reflect a substantial change in its policy objectives, since the mobility requirement did not apply any more. The requirement applies however to the whole period of our study: 2005-2009.

${ }^{13}$ http://www.anirc.com/wp-content/uploads/2013/11/20121122_NotaDePrensa_ANIRC.pdf, last accessed June, 2014.

${ }^{14}$ To obtain sample homogeneity within the group of Physicists we deleted Astrophysicists from the sample. Astrophysicists follow different collaboration and mobility patterns than the rest of Physicists 
PREPRINT version

This paper has been published in Science, Technology and Society, Vol. 20(3), 322-348

(Wagner, 2005). For instance, they show very large numbers of co-authors and short-term mobilities compared to the latter.

15 In the period considered in the study (2005-2009) these fields received 975, 507 and 790 applications respectively out of a total of 8,201 .

${ }^{16}$ For example, the definition of the 'Medicine' field changed over the years and the field was divided into 'Biomedicine', 'Clinical medicine' and 'Farmacology'.

${ }^{17}$ Sample figures show the results of weighted figures that have been applied in the study. The original sample has 63 observations per disciplines. They were selected departing from the 63 cases of Physics that complied with the conditions set above. Assuming the 'principle of maximum variance', it was obtained an error rate below 25\% (for a type error I of 0.05) that justified this figure (see Andujar, 2012 for more information on the sample). Instead of adjusting the sample per discipline according to the populations' percentages reducing the number of observations (max. per discipline 63), we have included all the cases in order to have a larger sample and include weights. The results presented in the paper are consistent when considering weighted and unweighted values.

18 To find out this information, we checked the dates of both the international stay and the participation in projects as well as the mobility's destination and funding organisation of the projects. In cases of doubt, the institutional affiliation of the PI was also searched in Google.

${ }^{19}$ Since this information is not a specific field of the Ramón y Cajal standarised CV, it was deduced from different sections of the $\mathrm{CV}$ : current positions, past experience or mobility experience in which the applicant could include it.

${ }^{20}$ These results are consistent when we consider un-weighted data $[($ Pearson $\operatorname{chi} 2(2)=13.2970 \operatorname{Pr}=$ 0.001); (Pearson chi2(2) $=14.3356 \mathrm{Pr}=0.001)]$.

\section{References}

Aceituno, P. (2013). Octavo informe INNOVACEF: estrategias para mejorar el sistema español de I+D+i. Revista de Trabajo y Seguridad Social, 365-366, 1-68.

Ackers, L. (2005). Moving people and knowledge: Scientific mobility in the European Union. International Migration, 43, 5, 99-131. 
Ackers, L., B. Gill and J. Guth (2008). 'Doctoral mobility in the Social Sciences'. Report to the NORFACE ERA-NET.

Adams, W. (1968). The brain drain. New York: The Macmillan Company.

Andújar, I. (2012). La movilidad internacional de los investigadores y las redes científicas de colaboración: dos dinámicas entrelazadas. Un estudio desde la Economía del Conocimiento. Unpublished doctoral dissertation, University Rey Juan Carlos, Madrid.

Balmer, B., M. Godwin and J. Gregory (2009). The Royal Society and the 'brain drain': natural scientists meet social science. Notes \& Records of the Royal Society. Retrieved June, 2012, from: doi:10.1098/rsnr.2008.0053.

Baruffaldi, S. H. and P. Landonib (2012). Return mobility and scientific productivity of researchers working abroad: The role of home country linkages. Research Policy, 41, $1655-1665$.

Brandi, M.C. (2006). The historical evolution of highly qualified migrations. Retrieved October, 2011, from: http://www.irpps.cnr.it/sito/curricula/curr_brandi.htm.

Brücker H., Capuano, S. and Marfouk, A. (2013). Education, gender and international migration: insights from a panel-dataset 1980-2010, mimeo.

Casey, T., S. Mahroum, K. Ducatel and R. Barré (2001). The Mobility of Academic Researchers. Academic Careers and Recruitment in ICT and Biotechnology. Report EUR 19905 EN, JCR/IPTS-ESTO. Sevilla: European Communities.

Cassarino, J.P. (2004). Theorising Return Migration: a revisited conceptual approach to return migrants. EUI working papers, 1-33. European University Institute: San Domenico di Fiesole.

COSCE (2005). Comisiones de Reflexión y Estudio de la Ciencia en España (CRECE). Ed. Rubes, Barcelona.

Cruz-Castro, L., Sanz-Menéndez, L. and Aja Valle, J. Junio (2006). Las trayectorias profesionales y académicas de los profesores de universidad y los investigadores del CSIC. Retrieved June, 2014, from: http://digital.csic.es/bitstream/10261/1667/1/dt0608.pdf

De Filippo, D. E. Sanz and I. Gómez (2007). Movilidad de investigadores y producción en coautoría para el estudio de la colaboración científica. Revista CTS, 3, 8, 23-40.

De Filippo, D., E. Sanz Casado and I. Gómez (2009). Quantitative and qualitative approaches to the study of mobility and scientific performance: a case study of a Spanish university. Research Evaluation, 18, 3, 1-10. 
Edler, J. and K. Stefan (eds.). (2003). Changing governance of research and technology policy. The European Research Area. Cheltenham: Edward Elgar.

European Commission - EC (2010). EUROPE 2020. A strategy for smart, sustainable and inclusive growth. Brussels: COM (2010) 2020.

European Commission - EC (2014). Innovation Union Scoreboard 2014. Belgium: European Union.

ERAC (2014). ERAC Peer Review of Spanish Research and Innovation System Final Report. MINECO.

FJI (2007). Informe de carrera investigadora en España. Carrera investigadora en España: deficiencias y propuestas. Retrieved June, 2012, from: (http://belasartes.uvigo.es/escultura/_documentos/_not_documentos/CARPETA5/Infor me_CI_final_agosto07.pdf)

Fernández-Zubieta, A. (2014). ERAWATCH Country Report 2012: Spain. Luxembourg: Publications Office of the European Union.

Fontes, M. (2007). Scientific mobility policies: how Portuguese scientists envisage the return home. Science and Public Policy, 34, 4, 284-298.

Franzoni, C., G. Scellato and P. Stephan (2012). Foreign-born scientists: mobility patterns for 16 countries. Nature Biotechnology, 30, 1250-1253.

Gaillard, A. M. and J. Gaillard (1997). The International Mobility of Brains: Exodus or Circulation?. Science Technology \& Society, 2, 195-228.

Gaillard, A. M. and J. Gaillard (1998). The international circulation of scientists and technologists. Science Communication, 20, 1, 106-116.

Gaillard, A. M. and J. Gaillard (1999). Les enjeux des migrations scientifiques internationals. De la quête de savoir à la circulation des compétences. Paris: L'Harmattan.

Gibbons, M., C. Limoges, H. Notwotny, S. Schwartzman and P. Scott (Ed.). (1994). The New Production of Knowledge. London: Sage.

Herreros-Chandro, I. (2013). La ciencia en la dictadura. El sistema nacional de I+D durante el franquismo (1939-1975), Revista Claseshistoria. Artículo No357, 15 de abril. Retrieved June, 2014, from: www.claseshistoria.com,

Jonkers, K. and R. Tijssen (2008). Chinese researchers returning home: impacts of international mobility on research collaboration and scientific productivity. Scientometrics, 77, 2, 309-333. 
Jöns, H. (2007). Transnational mobility and the spaces of knowledge production: a comparison of global patterns, motivations and collaborations in different academic fields. Social Geography, 2, 97-114.

Jöns, H. (2008). Academic travel from Cambridge University and the formation of centres of knowledge. Journal of Historical Geography, 34, 338-362

Jöns, H. (2009). Brain circulation' and transnational knowledge networks: studying long-term effects of academic mobility to Germany, 1954-2000. Global Networks, 9, 3, 315-338.

Krishna, V. V. and B. Khadria (1997). Phasing scientific migration in the context of brain gain and brain drain in India. Science Technology Society, 2, 2, 347-385.

Laudel, G. (2005). Migration currents among the scientific elite. Minerva, 43, 377-395.

Liberman, S. y K. B. Wolf (1997). The flow of knowledge: Scientific contacts in formal meetings. Social Networks, 19, 3, 271-283.

Mahroum, S. (2000). Highly skilled globetrotters: the international migration of human capital. Journal of R\&D Management, 30, 1, 23-32.

Marinelli, E., A. Fernández-Zubieta and S. Elena-Perez (2014). International job mobility and career consolidation of European researchers. In Marcel Gerard and Silke Uebelmesser (eds) The mobility of Students and the Highly Skilled. 83-104. Cambridge, CESifo Book Series. The MIT Press.

Melin, G. (2004). Postdoc abroad: inherited scientific contacts or establishment of new networks?. Research Evaluation, 13, 2, 95-102.

Meyer, J.B. and M. Brown (1999). Scientific diasporas: A new approach to brain drain. UNESCO-MOST Discussion Paper $\mathrm{N}^{\circ} 41$.

Meyer, J.B. (2001). Network Approach versus Brain Drain: lessons from the diaspora. International Migration Quarterly Review, 39, 5, 91-110. Special Issue, December.

MICINN (2011). 10 años del Programa Ramón y Cajal. Informe de resultados. Spanish Ministry for Science and Innovation. Retrieved June, 2014, from: http://www.idi.mineco.gob.es/stfls/MICINN/Investigacion/FICHEROS/FicherosNotasP rensa/ResultadosEncuesta10RyC\%20final_web.pdf

MINECO (2013a). Memoria de actividades de I+D+I 2012. FECYT. Retrieved June, 2014, from: http://www.idi.mineco.gob.es/stfls/MICINN/PlanNacional/20082011/FICHEROS/Resumen_Ejecutivo_Memoria_Actividades_IDI_2012.pdf

MINECO (2013b). Estrategia española de ciencia, tecnología e innovación 2013-2020. Ministerio de Economía y Competitividad. Retrieved June, 2014, from: (http://www.idi.mineco.gob.es/stfls/MICINN/Investigacion/FICHEROS/Estrategia_esp anola_ciencia_tecnologia_Innovacion.pdf) 
MORE (2010). Study on mobility patterns and career paths of EU researchers. Technical Report 2 - Part I: Mobility Survey of the Higher Education Sector. Retrieved July, 2011, from:

http://ec.europa.eu/euraxess/pdf/research_policies/MORE_HEI_report_final_version.pd f).

Salt, J. (1997). International movement of the highly skilled. OECD Occasional Paper no 3. Paris: OECD, International Migration Unit.

Sanz-Menéndez, L. and L. Cruz-Castro (2005). Explaining the science and technology policies of regional governments. Regional Studies, 39, 7, 939-954.

Saxenian, A.L. (2005). From brain drain to brain circulation: Transnational communities and regional upgrading in India and China. Studies in Comparative International Development, 40, 2, 35-61.

Song, H. (1997). From Brain Drain to Reverse Brain Drain: Three Decades of Korean Experience. Science Technology \& Society, 2, 2, 317-345.

Thorn, K. and L. B. Holm-Nielsen (2006). Mobility of Researchers and Scientists Policy Options for Turning a Drain into a Gain Research Paper No. 2006/83. UNUWIDER.

Turpin, T., R. Woolley, J. Marceau and S. Hill (2008) 'Conduits of knowledge in the Asia Pacific: research training, networks and country of work', Asian Population Studies, 4(3): 247-265.

Van de Sande, D., H.L. Ackers and B. Gill (2005). Impact assessment of the Marie Curie fellowships under the 4th and 5th Framework Programs of Research and Technological Development of the EU (1994-2002). Retrieved Novemeber, 2010, from: (http://ec.europa.eu/research/fp6/mariecurie-actions/pdf/impact_fellow_en.pdf).

Wagner, C. S. (2005). Six case studies of international collaboration in science. Scientometrics, 62, 1, 3-26.

Woolley, R., T. Turpin, J. Marceau and S. Hill (2008). Mobility Matters: Research Training and network building in Science. Comparative Technology Transfer and Society, 6, 3, 159-184. 
PREPRINT version

This paper has been published in Science, Technology and Society, Vol. 20(3), 322-348

\section{TABLES}

Table 1. Public funding for $R \& D$ distributed by national authorities (AGE) and Human Resources program (in millions EUR)

\begin{tabular}{|l|c|c|c|c|c|}
\hline \multicolumn{1}{|c|}{ Concept } & $\mathbf{2 0 0 8}$ & $\mathbf{2 0 0 9}$ & $\mathbf{2 0 1 0}$ & $\mathbf{2 0 1 1}$ & $\mathbf{2 0 1 2}$ \\
\hline Total funding for annual calls & $3.633,2$ & $3.567,9$ & $3.461,5$ & $3.323,7$ & $1.846,4$ \\
\hline $\begin{array}{l}\text { Funding for the "human resources } \\
\text { instrumental line of action" }\end{array}$ & 395,5 & 362,9 & 313,3 & 271,4 & 161,8 \\
& $(10.9 \%)$ & $(10.1 \%)$ & $(9.0 \%)$ & $(8.2 \%)$ & $(8.8 \%)$ \\
\hline - National Training Program & 155 & 160,5 & 104,6 & 15,4 & 130,2 \\
& $(4.3 \%)$ & $(4.5 \%)$ & $(3.0 \%)$ & $(0.5 \%)$ & $(7.1 \%)$ \\
\hline - National Hiring Program & 194,1 & 163,4 & 185,4 & 161,9 & 25,6 \\
& $(5.3 \%)$ & $(4.6 \%)$ & $(5.4 \%)$ & $(4.9 \%)$ & $(1.4 \%)$ \\
\hline - National Mobility Program & 46,4 & 39 & 23,3 & 94 & 6 \\
& $(1.3 \%)$ & $(1.1 \%)$ & $(0.0 \%)$ & $(2.8 \%)$ & $(0.3 \%)$ \\
\hline
\end{tabular}

Source: Annual reports of R\&D activities, Downloaded from MINECO web page (http://www.idi.mineco.gob.es/portal/site/MICINN/menuitem.7eeac5cd345b4f34f09dfd1001432ea0/?vgn extoid=888f66e17aa73210VgnVCM1000001d04140aRCRD ). Last accessed June, 2014. 
PREPRINT version

This paper has been published in Science, Technology and Society, Vol. 20(3), 322-348

Table 2. Distribution of the population and sample of the R\&D Applicants

\begin{tabular}{lcccc}
\hline & \multicolumn{2}{c}{ Population } & \multicolumn{2}{c}{ Sample } \\
& $\mathbf{N}^{\mathbf{0}}$ & $\mathbf{\%}$ & $\mathbf{N}$ & $\boldsymbol{\%}$ \\
\hline Physics & 472 & $31.4 \%$ & 59 & $31.4 \%$ \\
Agriculture & 408 & $27.1 \%$ & 51 & $27.1 \%$ \\
Molecular Biology & 623 & $41.5 \%$ & 78 & $41.5 \%$ \\
\hline Total & $\mathbf{1 5 0 3}$ & $\mathbf{1 0 0 . 0 \%}$ & $\mathbf{1 8 9}$ & $\mathbf{1 0 0 . 0 \%}$ \\
\hline
\end{tabular}


Table 3. Categories of the types of collaborations (Collaboration dynamics)

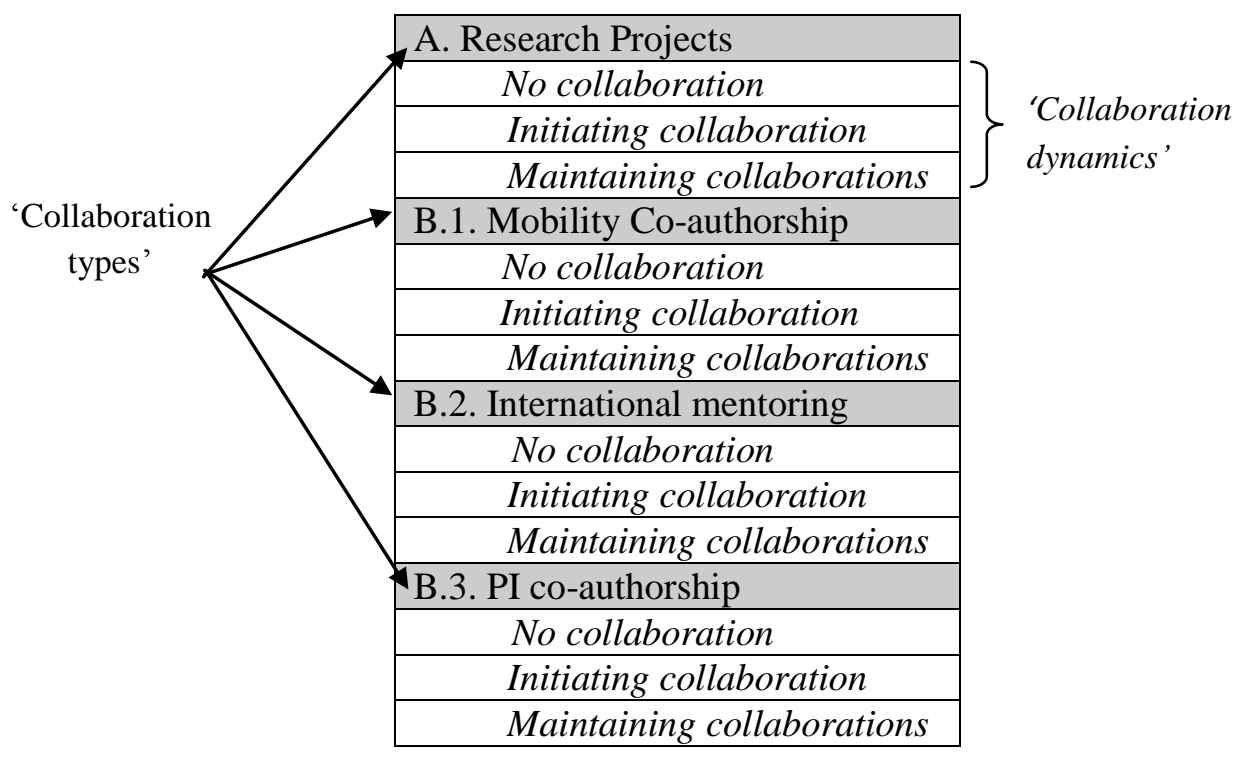

\begin{tabular}{|c|c|c|c|}
\hline A. Research Projects & Item 1 & Item 2 & \multirow{4}{*}{$\begin{array}{l}\text { Item } 1 \text {. The mobile researcher participates in a } \\
\text { research project developed in the home- } \\
\text { country during the mobility (yes }=1 / \text { no }=0 \text { ) } \\
\text { Item } 2 \text {. The mobile researcher participates in a } \\
\text { research project developed in the host } \\
\text { organisation during the mobilty (yes }=1 / \text { no }= \\
\text { 0) }\end{array}$} \\
\hline No collaboration & $\mathrm{No} / \mathrm{Yes}$ & No & \\
\hline Initiating collaboration & No & Yes & \\
\hline Maintaining collaborations & Yes & Yes & \\
\hline B.1. Mobility Co-authorship & Item 3 & Item 4 & \multirow{4}{*}{$\begin{array}{l}\text { Item } 3 . \text { The mobile researcher co-publishes } \\
\text { with the host PI before the mobility (yes }=1 \text { / } \\
\text { no }=0 \text { ) } \\
\text { Item } 4 \text {. The mobile researcher co-publishes } \\
\text { with the host PI during the mobility (yes }=1 / \\
\text { no }=0 \text { ) }\end{array}$} \\
\hline No collaboration & $\mathrm{No} / \mathrm{Yes}$ & No & \\
\hline Initiating collaboration & $\mathrm{No}$ & Yes & \\
\hline Maintaining collaborations & Yes & Yes & \\
\hline B.2. International mentoring & Item 5 & Item 6 & \multirow{4}{*}{$\begin{array}{l}\text { Item } 5 . \text { The mobile researcher co-publishes } \\
\text { with prior collaborators (previous to the } \\
\text { mobility) during the mobility (yes }=1 / \text { no }= \\
\text { 0) } \\
\text { Item } 6 . \text { The mobile researcher co-publishes } \\
\text { with new collaborators during the mobility } \\
\text { (yes }=1 / \text { no }=0 \text { ) }\end{array}$} \\
\hline No collaboration & $\mathrm{No} / \mathrm{Yes}$ & $\mathrm{No}$ & \\
\hline Initiating collaboration & $\mathrm{No}$ & Yes & \\
\hline Maintaining collaborations & Yes & Yes & \\
\hline B.3. PI co-authorship & Item 7 & Item 8 & \multirow{4}{*}{$\begin{array}{l}\text { Item } 7 \text {. A prior PI of the mobile researcher co- } \\
\text { publishes with the host PI before the mobility } \\
\text { (yes }=1 / \text { no }=0 \text { ) } \\
\text { Item } 8 \text {. A prior PI of the mobile researcher co- } \\
\text { publishes with the host PI during the mobility } \\
\text { (yes }=1 / \text { no }=0 \text { ) }\end{array}$} \\
\hline No collaboration & No/Yes & No & \\
\hline Initiating collaboration & $\mathrm{No}$ & Yes & \\
\hline Maintaining collaborations & Yes & Yes & \\
\hline
\end{tabular}


This paper has been published in Science, Technology and Society, Vol. 20(3), 322-348

Table 4. Country destinations by length of the stay

\begin{tabular}{|c|c|c|c|}
\hline & & uration & \\
\hline & Short & Long & Total \\
\hline & $\%$ & $\%$ & $\%$ \\
\hline US & $31.7 \%$ & $37.2 \%$ & $35.3 \%$ \\
\hline UK & $19.0 \%$ & $26.7 \%$ & $24.1 \%$ \\
\hline Germany & $7.6 \%$ & $11.1 \%$ & $9.9 \%$ \\
\hline France & $11.0 \%$ & $6.4 \%$ & $7.9 \%$ \\
\hline Netherlands & $3.8 \%$ & $5.9 \%$ & $5.2 \%$ \\
\hline Italy & $6.9 \%$ & $3.3 \%$ & $4.5 \%$ \\
\hline Switzerland & $2.9 \%$ & $2.7 \%$ & $2.8 \%$ \\
\hline Canada & $4.2 \%$ & $1.0 \%$ & $2.1 \%$ \\
\hline Belgium & $4.4 \%$ & $0.0 \%$ & $1.5 \%$ \\
\hline Sweden & $0.0 \%$ & $2.0 \%$ & $1.3 \%$ \\
\hline Portugal & $0.0 \%$ & $1.8 \%$ & $1.2 \%$ \\
\hline Austria & $1.5 \%$ & $0.7 \%$ & $0.9 \%$ \\
\hline Denmark & $1.3 \%$ & $0.8 \%$ & $0.9 \%$ \\
\hline Israel & $1.5 \%$ & $0.7 \%$ & $0.9 \%$ \\
\hline Australia & $1.5 \%$ & $0.0 \%$ & $0.5 \%$ \\
\hline Mexico & $1.5 \%$ & $0.0 \%$ & $0.5 \%$ \\
\hline Norway & $1.5 \%$ & $0.0 \%$ & $0.5 \%$ \\
\hline Total & $100 \%$ & $100 \%$ & $100 \%$ \\
\hline
\end{tabular}


PREPRINT version

This paper has been published in Science, Technology and Society, Vol. 20(3), 322-348

Table 5. Descriptive statistics

\begin{tabular}{|c|c|c|c|c|c|}
\hline Variable & Obs & Mean & Std. Err. & Min & Max \\
\hline Return & 189 & 0.466 & 0.037 & 0 & 1 \\
\hline Duration & 189 & 0.659 & 0.034 & 0 & 1 \\
\hline Research projects & 189 & & & & \\
\hline No collaboration & & 0.308 & 0.034 & 0 & 1 \\
\hline Initiating collaboration & & 0.347 & 0.036 & 0 & 1 \\
\hline Maintaining collaborations & & 0.345 & 0.035 & 0 & 1 \\
\hline Mobility co-authorships & 189 & & & & \\
\hline No collaboration & & 0.085 & 0.020 & 0 & 1 \\
\hline Initiating collaboration & & 0.160 & 0.028 & 0 & 1 \\
\hline Maintaining collaborations & & 0.755 & 0.032 & 0 & 1 \\
\hline International mentoring & 189 & & & & \\
\hline No collaboration & & 0.377 & 0.036 & 0 & 1 \\
\hline Initiating collaboration & & 0.538 & 0.037 & 0 & 1 \\
\hline Maintaining collaborations & & 0.085 & 0.021 & 0 & 1 \\
\hline PI co-authorships & 189 & & & & \\
\hline No collaboration & & 0.882 & 0.024 & 0 & 1 \\
\hline Initiating collaboration & & 0.059 & 0.017 & 0 & 1 \\
\hline Maintaining collaborations & & 0.059 & 0.018 & 0 & 1 \\
\hline Age & 189 & 38.391 & 0.247 & 30.968 & 55.570 \\
\hline Experience & 189 & 9.143 & 0.173 & 4.561 & 15.280 \\
\hline Precocity & 189 & 0.529 & 0.037 & 0 & 1 \\
\hline Publications & 189 & 0.808 & 0.070 & 0 & 7 \\
\hline Returning Financial Support & 189 & 0.183 & 0.028 & 0 & 1 \\
\hline Outgoing Financial Support & 189 & & & & \\
\hline Other & & 0.453 & 0.037 & & \\
\hline National & & 0.305 & 0.034 & 0 & 1 \\
\hline International & & 0.242 & 0.032 & 0 & 1 \\
\hline Sex (female) & 189 & 0.438 & 0.037 & 0 & 1 \\
\hline Discipline & 189 & & & & \\
\hline Physics & & 0.314 & 0.034 & & \\
\hline Agriculture & & 0.271 & 0.031 & 0 & 1 \\
\hline Molecular Biology & & 0.415 & 0.038 & 0 & 1 \\
\hline
\end{tabular}


PREPRINT version

This paper has been published in Science, Technology and Society, Vol. 20(3), 322-348 
Table 6. Duration of the stay and collaboration dynamics of research projects and co-authorships

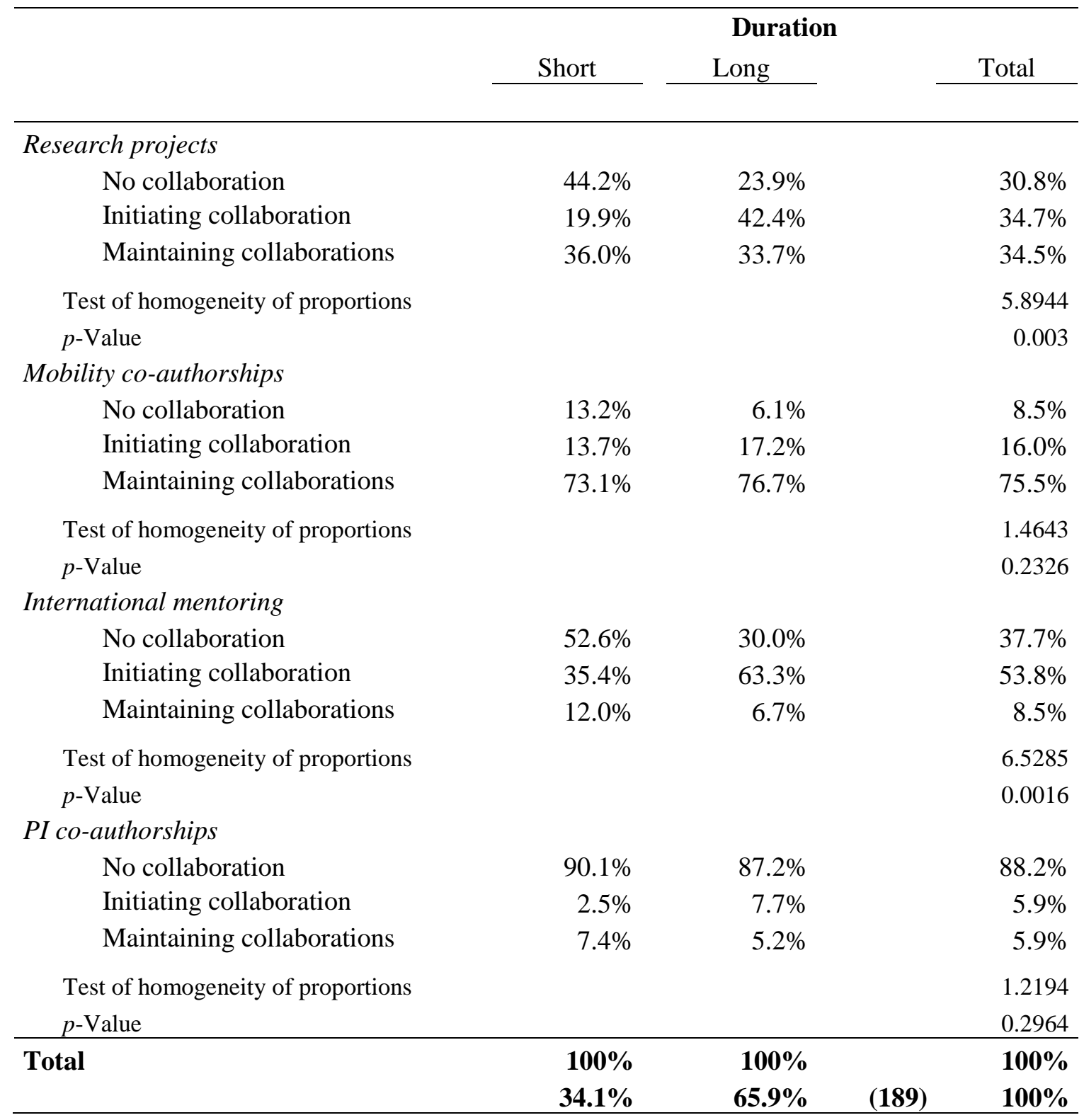


PREPRINT version

This paper has been published in Science, Technology and Society, Vol. 20(3), 322-348

Table 7. Regression

\begin{tabular}{|c|c|}
\hline \multicolumn{2}{|l|}{ Return } \\
\hline Duration & $\begin{array}{c}-1.828 * * * \\
(0.556)\end{array}$ \\
\hline \multicolumn{2}{|l|}{ Research projects (No collaboration) } \\
\hline Initiating collaboration & $\begin{array}{c}0.780 \\
(0.914)\end{array}$ \\
\hline Maintaining collaboration & $\begin{array}{c}1.048 \\
(0.938)\end{array}$ \\
\hline \multicolumn{2}{|l|}{ Mobility Co-authorship (No collaboration) } \\
\hline Initiating collaboration & $\begin{array}{r}-0.928 \\
(0.981)\end{array}$ \\
\hline Maintaining collaboration & $\begin{array}{l}-0.762 \\
(0.905)\end{array}$ \\
\hline \multicolumn{2}{|l|}{ International mentoring (No collaboration) } \\
\hline Initiating collaboration & $\begin{array}{c}-0.597 \\
(0.883)\end{array}$ \\
\hline Maintaining collaboration & $\begin{array}{l}-1.018 \\
(1.597)\end{array}$ \\
\hline \multicolumn{2}{|l|}{ PI co-authorships (No collaboration) } \\
\hline Initiating collaboration & $\begin{array}{c}-2.590 * * * \\
(0.846)\end{array}$ \\
\hline Maintaining collaboration & 1.073 \\
\hline$x_{1}$ & $\begin{array}{c}-0.365^{* * *} \\
(0.134)\end{array}$ \\
\hline Experience & $\begin{array}{c}0.876^{* * * *} \\
(0.220)\end{array}$ \\
\hline Precocity & $\begin{array}{c}-1.477 * * \\
(0.682)\end{array}$ \\
\hline Publications & $\begin{array}{r}0.157 \\
(0.237)\end{array}$ \\
\hline Returning Financial Support & $\begin{array}{c}4.562 * * * \\
(1.244)\end{array}$ \\
\hline \multicolumn{2}{|l|}{ Outgoing Financial Support } \\
\hline National & $\begin{array}{r}0.459 \\
(0.500)\end{array}$ \\
\hline International & $\begin{array}{c}0.455 \\
(0.571)\end{array}$ \\
\hline Sex (female) & $\begin{array}{r}0.239 \\
(0.435)\end{array}$ \\
\hline \multicolumn{2}{|l|}{ Discipline (Physics) } \\
\hline Agriculture & $\begin{array}{c}0.440 \\
(0.685)\end{array}$ \\
\hline Molecular Biology & $\begin{array}{l}-0.550 \\
(0.639)\end{array}$ \\
\hline Cons & $\begin{array}{l}7.499 * \\
(3.979)\end{array}$ \\
\hline $\mathbf{N}$ & 189 \\
\hline Pseudo R2 & 0.442 \\
\hline
\end{tabular}

Standard errors in parentheses 
PREPRINT version

This paper has been published in Science, Technology and Society, Vol. 20(3), 322-348

$* \mathrm{p}<.1, * * \mathrm{p}<.05, * * * \mathrm{p}<.01$ 